\title{
O que o olho não vê o coração também sente: como cuidar do invisível que nos salta aos olhos ${ }^{1}$
}

\section{What the eyes doesn't see, the hart also feels: how to take care of the invisible that jumps to the eyes}

\section{Lo que los ojos no ven el corazón lo siente: cómo "cuidar" lo invisible que aparece frente a nuestros ojos}

\section{Eleonôra Torres Prestrelo*}

Universidade do Estado do Rio de Janeiro - UERJ, Rio de Janeiro, Rio de Janeiro, Brasil

\begin{abstract}
RESUMO
Este artigo nasce de inquietações e questionamentos disparados por ecos das falas de alunos da Graduação em Psicologia. Acreditando que as disfunções relacionais se estabelecem pelo abandono da confirmação do outro enquanto ser legitimo em sua alteridade, a autora apresenta um projeto de extensão como espaço de acolhimento e cuidado na universidade, tema que se transformará, posteriormente, em objeto e método de sua pesquisa de doutorado. Em seu trabalho, referencia-se no cuidado que se dá como exigência ontológica dos mundos relacionais, na busca de ampliação de entendimento de nossos modos de existência. Inspirada na noção de cuidado desenvolvida por Annemarie Mol, a autora propõe em sua prática, inclusive a de pesquisa, a mapear, contactar e narrar o que é colocado à margem, os desacertos, os não ditos na elaboração do conhecimento em nossas pesquisas e com eles, talvez, tornar visível as demandas, articulações, afetações presentes no cotidiano acadêmico. Afinada com a diretriz de pesquisa do Laboratório PesquisarCOM (UFF), a autora afirma a pesquisa como uma prática performativa que se faz com o outro e não sobre o outro.
\end{abstract}

Palavras-chave: cuidar, cuidado, pesquisar, política ontológica.

\section{ABSTRACT}

This article arises from a sum of concerns and questions raised by undergraduate Psychology students' reverberations. Considering that one's desertion of its confirmation as legitimate human being is established by their relational dysfunctions, the author presents an extension project as a reception and care space at the university, theme that becomes later in object and method of her doctoral research. It In his work, reference is the care that is given as an ontological requirement of the related worlds expanding beyond the ethical or affective needed, aiming the understanding of existence modes. Inspired by Annemarie Mol 's notion of care, the author proposes, in his practice, including research, mapping, and contacting narrate that detect what is placed at margin, the mistakes, the unspoken in knowledge development during our research and with them, making visible 
the demands, articulations and academic's daily affectations. In association with PesquisarCOM Laboratory (UFF), the author states the research as a performative practice performed with each other and not above the other.

Keywords: care, caring, research, ontological politics.

\section{RESÚMEN}

Este artículo nace de una sumatoria de inquietudes y cuestionamientos, ecos de las palabras de los alumnos de graduación en psicología. Sosteniendo que las disfunciones relacionales se establecen por el abandono de la confirmación del otro en cuanto ser legitimo en su alteridad, la autora presenta un proyecto de extensión como espacio de acogida y cuidado en la universidad, tema que se convierte más tarde en objeto y método de investigación de doctorado al "cuidado" dado como exigencia ontológica de los mundos relacionales en la búsqueda de ampliar el entendimiento de nuestros modos de existencia. Inspirada en la noción de "cuidado" desarrollada por Annemerie Mol, la autora propone, en su práctica, incluyendo la investigación, la cartografía, y ponerse en contacto narran lo marginal, los desaciertos, lo no-dicho en la elaboración de nuestras investigaciones, y a partir de ello hacer visibles las demandas, articulaciones, afecciones presentes en el cotidiano académico. Siguiendo la directriz del Laboratorio de PesquisarCOM (UFF), la autora releva la investigación como una práctica performativa que se hace con el otro y no sobre el otro.

Palabras claves: cuidar, cuidado, investigar, política ontológica.

\section{Introdução}

Este artigo nasce de um somatório de inquietações, disparadas, em grande parte, por alguns fragmentos de histórias. Dentre muitas, parto de minha própria trajetória e de ecos das falas de alunos da Graduação em Psicologia, da instituição da qual faço parte como docente, que foram reverberando em mim numa busca de possibilidades de entendimento, um interesse em cuidar.

O mundo da psicologia é um mundo encantado. As pessoas são encantadoras, a profissão é encantadora; e você, claro, quer ser também uma dessas pessoas encantadoras... um encantador... é um mundo fantástico e você não acredita ter entrado ali. (...) Existe um sentimento ao entrar na faculdade que foge às palavras. (...)

No princípio, te perguntam a toda hora, a cada momento, o que você acha das aulas. E você: "legal". Esse "legal" é assim meio amarelo, meio sem gosto, meio apagado. (...) Mas você está destinado a ser um encantador, e seu encantamento te permite uma esperança sem limites. Então a certeza de que o próximo ano será melhor tem início. (Xisto, 2006, pp.224-225.)

\section{Como o cuidar me atravessa}


"Tudo é e não é..."

(Guimarães Rosa, 1986, p.5)

Desde a lembrança mais remota de minha infância percebo meu interesse em saber histórias, buscar-Ihes o sentido, me fazer ouvinte atenta e perspicaz desde as rodas de conversa na "casa de farinha" com os empregados da fazenda de minha avó paterna, nas conversas dos mais velhos, nas narrativas dos livros infantis... É da cultura nordestina o hábito de contar histórias, do ritmo cantante de seu sotaque a literatura emblemática de seu povo, o cordel.

É também dessa origem nordestina que trago, acredito, um sentido próprio para a noção de cuidado. Num lugar onde a seca quase tudo destrói deixando pouco para a sobrevivência, escutar a necessidade do outro se impõe como referência de humanidade.

Ampliando o olhar além da pessoalidade de minha história, atentemos para autores renomados como Guimarães Rosa, Ariano Suassuna, João Cabral de Melo Neto e Jorge Amado que, através de suas narrativas nos aproximam dessa realidade nos convocando a perceber o outro, a estar $\mathrm{com}^{2}$ o outro, numa proximidade que nos inclui reflexivamente numa realidade ímpar. Em muitos momentos, uma realidade de não escuta, de se sentir invisível, dispositivo que talvez seja o que me mova na proposta desse trabalho. Parto, então, de um lugar marcado, vivo, no sentido expresso por Haraway (1995) onde o cuidado não é teorizado, mas praticado intuitivamente como uma marca da sobrevivência, que se apresenta numa experiência típica da realidade nordestina.

[...] a imagem era do sertão nordestino, uma casa de taipa, como tantas já vistas; uma senhora idosa na janela, como tantas outras vistas, um repórter entrevistando um menino de mais ou menos 11 ou 12 anos. Cena nunca vista: um menino do sertão nordestino com um surrado calção, nu da cintura pra cima, com um livro de "Harry Potter" na mão...

[...] A câmara focava o rosto do menino, seus olhos redondos, grandes, intensos na emoção expressa ao olhar para o livro com ar de incredulidade, nas mãos que acariciavam o papel, virando-o de um lado pro outro, a emoção transbordando num peito arfante, difícil, senão impossível de se fazer palavras, que só a insistência do repórter pode concretizar.

Nunca esquecerei essa cena: foi mais do que sua expressão de felicidade, muito, muito mais... Foi a expressão da tristeza que, num segundo plano, se fazia figura, quando, insistentemente, ao agradecer ao desportista (assim me pareceu), que, por ocasião de sua passagem por ali teve a oportunidade de o saber um aficionado pelo personagem - dizia que achava que 


\section{devia ser assim, os que tinham mais deviam dividir com os que não tinham!!!}

Uma criança de 11 ou 12 anos, numa idade onde o mundo deveria ainda ser delineado por sonhos, fantasias, aventuras, já lidando com a dor subjacente à constatação da exclusão social. Uma criança privada da possibilidade de dar vazão à sua curiosidade, condição inerente ao "ser criança", de expandir sua aptidão para o desenho, mostrada pela reportagem, traduzido no discurso da mãe em se ver frustrando com tanta freqüência por total impossibilidade financeira, seus pedidos de que, ao ir à feira, trouxesse alguma revista ou chiclete que tivesse algum desses personagens pra que ele pudesse reproduzi-lo.

Impactada pela cena fiquei ali, comungando seu choro, seu apelo, e sua imagem tem me acompanhado por esses dias afora (Prestrelo, 2002, outubro).

Tornei-me uma psicóloga clínica, ofício cuja pratica cotidiana inclui ouvir e conjuntamente contar e recontar histórias e tornei-me, também, professora e supervisora de estágio de uma abordagem clinica, personagem em outras histórias. Ouvir, tornar visível aquilo que ainda não o foi, o que não tem nome, o indizível talvez. Fazer aparecer, cuidar do que "aparece"! Dois ofícios, a continuidade de uma história...

A melhor expressão de cuidado, dizem alguns autores (Ribeiro, 1998; Miller, 1997) seria a confirmação do outro enquanto ser legitimo em sua alteridade. As disfunções relacionais se estabelecem pelo abandono dessa perspectiva na busca de semelhanças, comparações, pretensa busca de universalidade, referência da uma ciência "moderna". Portanto, cuidar, além de se traduzir numa ação de atenção à necessidade do outro, implicaria em movimento primário de legitimação, o que requer implicação. I mplicação inclui emoção, a emoção, inevitavelmente, faz emergir a pessoalidade nas relações. Para que possamos acolher a pessoalidade precisamos estabelecer relações de cuidado no cotidiano. Seria essa a forma esperada e praticada de cuidado na Academia? Podemos ensinar a cuidar sem trazer para a academia a experiência de cuidar?

Ao pesquisar a experiência de adaptação de alunos à universidade, Teixeira, Dias, Wottrich e Oliveira (2008) ressaltam, “(...) o ingresso na universidade é, ao menos potencialmente, uma experiência estressora para os jovens estudantes (p.187)." e nos apresentam algumas falas que nos soam familiares em nossa experiência de ensino: "Foi em sete meses um estouro na cabeça. Tu muda completamente tua vida. Antes tu morava com o teu pai e com tua mãe e depois tu mora sozinho... Algo do dia pra noite, dá pra dizer..." (J oão, p.192) ou "Ah, tipo, tenho mais responsabilidade. Porque tu tá estudando pra ser um profissional, né?" (Karen, p. 193). 
Em todos esses anos na universidade percebi, muitas vezes, os alunos apontando para um lugar conhecido, o da não escuta, da invisibilidade no cotidiano. Apontam dicotomias e incoerências em sua formação de psicólogos que os fazem sentir-se desamparados:

Vida. Como fazer brotar vida das paredes de concreto da faculdade? Da universidade? Onde ela é produzida? As paredes de concreto discursam sobre quem você é. Estou no meu castelo e ele diz: você é. O que você é? Afinal, de que somos feitos? Quando você olha o outro, o que é que vê? Você deve olhar o outro... ser guardião dessa subjetividade, dizem os professores! Decifrador desse íntimo? Olho para a frente e vejo o longo corredor, de teto alto, imponente e concreto cru...a imagem que construí de mim e da Psicologia não se reflete em praticamente lugar algum. Você consegue se ver? Consegue ver o que elas produzem em você? (Xisto, 2006, pp.225-226).

Nas falas dos alunos o que aparece é como se os muros da instituição separassem dois mundos, do lado de dentro o aprender, do lado de fora o viver. O que fazemos com isso?

\section{O “GAPsi : Grupos de Apoio Psicológico" - cuidando do que o coração sente...}

Por informação, formação e, talvez, em decorrência de um "saber de experiência", não acredito haver a possibilidade de estudo do humano, de qualquer outro ser vivo e dos objetos (Latour, 2008; Despret, 1996; Mol, 2008), sem nossa inclusão nesse ato de apreensão, inclusive, ressalto, a inclusão de nossa dimensão sensível. Para transitar por esse tema, lançarei mão de algumas idéias de Bondía (2002), com as quais me identifico. Eminente filósofo da educação, este autor desenvolve uma crítica ferrenha à forma como tem se estabelecido na sociedade contemporânea e no sistema educacional, sua área de atuação mais próxima, a absorção de informação e sua equivocada identificação desta, como conhecimento. Chama-nos a atenção para o "saber de experiência", saber que vai se dando quando alguém vai dando sentido ao que the acontece no ato do acontecer. Diz-nos ele,

A experiência é o que nos passa, o que nos acontece, o que nos toca. Não o que se passa, não o que acontece, ou o que toca. A cada dia se passam muitas coisas, porém, ao mesmo tempo, quase nada nos acontece. Dir-se-ia que tudo o que se passa está organizado para que nada nos aconteça (2002, p.21) 
Sobre esse tema podemos trazer, também, para alimentar nosso diálogo, Luis Antonio Baptista (2000) que em seu livro "A Fábrica de Interiores: a formação psi em questão" problematiza a formação universitária de alunos de psicologia, "Podemos dizer parcialmente que, na aridez acadêmica, não há espaço para afetos e para calores humanos (p.37)". Neste livro ele nos traz, através da utilização da metáfora do funcionamento de uma fábrica, questionamentos relativos à formação do psicólogo clínico, especialmente na formação dos alunos no espaço de supervisão. Ressalta a falta de espaço para a construção de uma pessoalidade, insistência na reprodução de um modelo. Reproduzo, aqui, algumas das muitas falas desses alunos:

“Por exemplo, muita coisa que eu faço eu não falo pra ele. Eu não preciso falar pra ele porque eu sei que ele vai me criticar. Então eu acho que o que eu sinto, o meu estilo, não é muito aproveitado, não. Esse lance que a gente sente, o que a gente pensa não tem lugar na supervisão. A gente segue o modelo dele... (entrevistado 1986, p. 98)"

"O psicólogo é diferente das demais profissões, principalmente porque o trabalho dele não é uma coisa meio guiada. Você vai ao médico para ficar bom de alguma doença e toma remédio e fica bom. Procura um arquiteto para fazer a planta de sua casa. O psicólogo vai depender de você, vai depender do cliente. (...) Existe uma diferença bem grande (...)" (entrevistado 1987, p.10)

Autores como Bondía e Baptista, dentre tantos, me ajudam a pensar o ato de ensinar, na forma como o faço, nas marcas que instauro segundo meu fazer, pois acredito que pensar minha experiência me ajuda a dar sentido ao que faço - o caminho de construção de um cuidado não verticalizado professor/aluno e sim distribuído entre os vários atores que fazem parte dessa rede de formação profissional. Como muito bem nos lembra Moraes (2003), as redes não são amorfas: "Ela [a rede] consolida a potência do empírico como solo de invenção da razão, da verdade, da sociedade, da natureza (p. 538)." Atravessada pelas falas que reverberam nos corredores e salas de concreto da universidade, pelo histórico de tentativas e, por vezes, concretizações de suicídios na instituição por alunos de dentro e fora da universidade, a trágica expressão de um sofrimento invisível aos nossos olhos, fui abrindo espaço para a troca, a experimento-ação de outros lugares de escuta.

Tinha acabado, havia algum tempo, uma especialização em "Terapia Comunitária" (atualmente denominada Terapia Comunitária Integrativa), uma metodologia de trabalho em grupo elaborada pelo psiquiatra, antropólogo e professor da Universidade Federal do Ceará, Dr. Adalberto Barreto propícia para o trabalho em grandes grupos em 
situações de sofrimento. Ofereci-me para coordenar "Rodas de Terapia Comunitária" nas Semanas de Psicologia da universidade da qual faço parte, o que foi prontamente acolhido com muito entusiasmo pelos alunos. A oportunidade de participar, de conhecer algo voltado para a "comunidade"... "rodas" com uma média de 35 participantes, um entusiasmo contagiante!

Afetada pela repercussão do trabalho e pela procura de alguns alunos em saber e dele participar, elaborei, junto com estagiários, no ano de 2010, um projeto de extensão intitulado "Terapia Comunitária" onde me propunha a fazer "rodas" no Instituto de Psicologia e fora dele. Algumas incursões importantes foram realizadas por nós. Algumas dificuldades: a palavra terapia assusta a muitos; um trabalho que se mostre terapêutico parece ser visto com bastante resistência no espaço universitário; preconceitos, "aprisionamentos acadêmicos". Muito acolhimento. O se fazer de um caminho.

No ano de 2013 resolvemos mudar o nome do projeto de extensão para "GAPsi : grupos de apoio psicológico" em busca de maior liberdade metodológica no trabalho em grupo e adaptações às demandas do público alvo. Esse projeto se configura como um espaço de cuidado no âmbito da graduação em Psicologia do Instituto de Psicologia, favorecendo a criação de redes sociais de apoio. Se propõe a identificar práticas de cuidado desenvolvidas por e para a comunidade discente, mapeando suas formas e delineamentos. Acreditamos ser imprescindível performar práticas de cuidado pois, cuidando de nós também cuidaremos do outro, prerrogativa paradigmática do curso de psicologia.

Através do que denominamos "oficinas de cuidado", trabalhamos temas trazidos pelos próprios alunos, a fim de buscarmos a melhor forma de estudá-los e desenvolve-los. Os encontros atualmente duram, em média, 1:30 hs e acontecem quinzenalmente, sempre no mesmo horário, numa sala do SPA (Serviço de Psicologia Aplicada) do Instituto de Psicologia da UERJ. Esses encontros são divulgados pelas redes sociais disponíveis, pela lista de emails da secretaria do IP, do centro acadêmico dos estudantes, de nossas redes particulares, através de nosso perfil no Facebook do projeto e por cartazes afixados nos espaços internos da universidade. Existem também aqueles alunos que chegam pela divulgação realizada "boca a boca" por membros mais assíduos do grupo.

Ao nos reunirmos na sala, nos sentamos em círculo e nos debruçamos sobre o que o grupo coloca como questão naquele encontro, abrindo espaço para a escuta de suas inquietações, onde a autora coordena a discussão e propõe algumas dinâmicas de grupo, quando necessário, para facilitar o contato com o que está sendo vivido e a troca de experiências. Não há compromisso de regularidade e não nos propomos a ser um espaço psicoterapêutico. Da forma como se estrutura, o trabalho permite a construção de uma teia de 
relações sociais que potencializa o valor da troca de experiências e o resgate de uma dimensão sócio-política que pode propiciar a superação das adversidades, desenvolvendo a identificação do poder individual e coletivo do grupo, se constituindo, portanto, num campo de suporte acadêmico, social e afetivo. Além de temas específicos à vida acadêmica, também acolhemos um tipo de sofrimento que muitas vezes os permeiam e que não são absorvidos pelos serviços de saúde, os chamados "sofrimentos difusos" (Fonseca, 2007): um tipo de sofrimento caracterizado pela sensação de um mal estar generalizado, onde a pessoa apresenta múltiplos sintomas, tais como queixas somáticas inespecíficas, irritabilidade, insônia, nervosismo, dores no corpo, etc. Não são acolhidos, pois são sintomas que não fazem parte da clientela preferencial da clínica médica e nem da saúde mental, embora se configurem em importante demanda de atendimento na atenção básica.

\section{O Cuidar como ação}

"O senhor... Mire veja: o mais importante e bonito, do mundo, é isto: que as pessoas não estão sempre iguais, ainda não foram terminadas - mas que elas vão sempre mudando. Afinam ou desafinam. Verdade maior. É o que a vida me ensinou. Isso que me alegra, montão. (Guimarães Rosa, 1986, p.15)"

$\mathrm{O}$ ato de cuidar se configura, para mim, atualmente, em ação no cotidiano; na clínica, nos projetos de extensão que coordeno como o GAPsi e o "Laboratório Gestáltico: configurações e práticas contemporâneas" e como tema da pesquisa que pretendo desenvolver no doutorado, o que vejo como práticas indissociáveis. 0 cuidar como exigência ontológica dos mundos relacionais, que vai além de uma exigência ética ou afetiva (Puig de la Bellacasa, 2012).

O cuidar se constitui em tema importante na área dos estudos de Ciência, Tecnologia e Sociedade, área com a qual nosso grupo de pesquisa dialoga 3 , seja na problematização de sua lógica, seja na importância dada à escrita, seja no cuidado no ato de pesquisar (Moll, 2007; Haraway,1995; Puig de la Bellacasa, 2012; Zanella, 2013). Cuidar do pensar, do pesquisar, do registrar, pois, como nos alerta Haraway (1995), o conhecimento produz mundos!

\subsection{A política ontológica de Annemarie Moll}

Nesse trabalho utilizo como inspiração a noção de cuidado desenvolvida pela filósofa e médica holandesa Annemarie Mol. Segundo a perspectiva dessa autora, no texto "The logic of care" 
(2008) o cuidado se dá no fazer, não existe enquanto uma forma "a priori" e o "bom cuidado" seria inerente a uma perspectiva que leva em conta uma especificidade, uma vida em ação. A ênfase dessa autora numa vida que se faz ao vivê-la, na ação, na experimentoação, eu complementaria, e, no caso, na criação de dispositivos de cuidado que se produzem sempre nas relações me tem sido especialmente cara. A utilização desse referencial teórico consiste, a meu ver, na possibilidade de ampliação de entendimento do campo de relações que performam nossos modos de existência.

A partir de experiências pessoais e pesquisas etnográficas realizadas, Mol, neste livro, desenvolve ampla discussão sobre a lógica do cuidado, ponto central do livro, e seu contraponto, a lógica da escolha, o que implica uma postura crítica ao que muitas vezes se constitui como tal, tratando do tema, debruçando-se sobre a forma como se trabalha com pessoas com diabetes. Para isso, chama atenção no texto para nossa responsabilidade enquanto atores/autores na construção de práticas, inclusive de pesquisa, que perpetuem o que chamaria de "mau cuidado".

Para o que nos interessa nesse texto, a reflexão sobre as possibilidades de práticas de cuidado no cotidiano acadêmico, nos deteremos no que a autora se refere como uma "lógica do cuidado", deixando para outro momento maior detalhamento da "lógica da escolha".

O "bom cuidado", ou o cuidado bom o suficiente, segundo essa autora, se constitui na prática, entendendo esse termo como algo em constante processo de se fazer, como vimos anteriormente no texto. Portanto, adota a perspectiva de que o mundo não está pronto, que ele se constrói nas relações e, principalmente, num fazer, ao invés de adotar uma noção de cuidado pré-estabelecida o que contrariaria a noção de construção do conhecimento pertinente a alguns autores (Moll, 2008a; Haraway,1995; Puig de la Bellacasa, 2012; Zanella, 2013), dentre tantos outros com os quais dialogamos em nossos trabalhos.

Partindo dessas falas e de tantas outras, me pergunto que práticas seriam possíveis no estabelecimento do que Mol (2008a) poderia chamar de um "bom cuidado" por parte dos atores envolvidos nessa relação: alunos, professores, funcionários, estrutura física da instituição, o que pretendemos mapear na pesquisa de doutorado a ser desenvolvida. Para identificá-las, acredito que só uma prática que faça falar todos esses atores/autores poderia nos ajudar,

Se as práticas são colocadas no primeiro plano não há mais um simples objeto passivo no meio, esperando ser visto do ponto de vista de séries intermináveis de perspectivas. Ao contrário, os objetos existem - e desaparecem - com as práticas através das quais eles são manejados. $\mathrm{E}$ desde que o manejo tende a 
diferir de uma prática a outra, a realidade se multiplica. [...] no modo filosófico no qual eu me engajo aqui, conhecimento não é uma questão de referência, mas de manejo (Mol, 2002, p. 5).

O modo filosófico privilegiado pela autora onde o manejo constitui - conhecimento e não uma referência teórica pré-definida nos é particularmente enriquecedor, inovador e se apresenta como questão central em nosso trabalho. Ou seja, o conhecimento se construiria na prática, no caso, o cuidar, num fazer contínuo, daí porque seria único, múltiplo. Não existe um domínio a recuperar, a importância reside na identificação de um estilo, uma forma de fazer. Afinamo-nos, portanto, com uma orientação da prática que acredita que a produção do conhecimento se faz através de uma rede, num entrelaçar de saberes que se fazem-com o outro e não sobre o outro - o PesquisarCOM, cunhado por Moraes (2010), citado anteriormente, que afirma uma orientação de pesquisa que apresenta um olhar para a relação entre pesquisador e seu objeto de pesquisa onde ambos afetam-se mutuamente, onde o outro não se configura como um qualquer e sim aquele que, em relação, constrói, conosco, um novo saber. Pensar 0 cuidado sob essa perspectiva resgata 0 encantamento da construção de um conhecimento vivo, liberto das grades metodológicas de uma prática de pesquisa reducionista.

Entendo que alguns autores da área de estudos Ciência, Tecnologia e Sociedade podem ampliar a compreensão desse campo, somando às abordagens de inspiração fenomenológico-existencial, por exemplo, a compreensão de uma realidade que se dá no fazer e que está sendo feita na vinculação de uma rede de atores, humanos, não-humanos, seres híbridos que somos.

Aliás, sobre sermos "humanos", Haraway \& Kunzru (2009) levanta interessante discussão que, embora não seja o momento de desenvolvê-la, vale à pena, mesmo que rapidamente, pontuarmos aqui, já que tangencia o tema desse trabalho: neste excelente ensaio ela coloca em questão a distinção entre a máquina e a construção do que denominamos "ser humano": "No final do século XX, neste nosso tempo, um tempo mítico, somos todos quimeras, híbridos - teóricos e fabricados - máquina e organismo; somos, em suma, ciborgues. 0 ciborgue é nossa ontologia: ele nos dá nossa política (p.37)".

Pesquisar levando em consideração todos esses elementos, humanos, não-humanos, ciborgues, a vida se fazendo, se refere à tentativa de apreensão dos nossos modos de existência. Levar em consideração esses elementos e narrá-los em nossos trabalhos de pesquisa constitui o que Mol (2008b) denomina uma "política ontológica"

A combinação dos termos "ontologia" e "política" sugere-nos que as condições de possibilidade não são dadas à partida. Que a realidade não precede as práticas banais nas quais 
interagimos com ela, antes sendo modelada por essas práticas. O termo política, portanto, permite sublinhar este modo ativo, este processo de modelação, bem como o seu caráter aberto e conectado. (p.64).

Alimenta-me a perspectiva de construção de um conhecimento vivo, não aquele pautado na reprodução infinita de pensamentos e ações anteriores que se distanciam, com freqüência, do que costumo chamar de uma "vida vivida", não apenas pensada, sonhada, projetada, idealizada. Uma noção de construção do conhecimento que atente para a utilização de uma metodologia de pesquisa que contemple a complexidade da vida, que encare 0 ato de pesquisar como um processo de criação "(...) e a pesquisa realizada como objetivação de uma atividade criadora que se apresenta como obra a ser lida, degustada, devorada, deglutida. Obra que reinventa a própria vida, em vez de somente explicá-la ou compreendê-la (Zanella, 2013, p.21)".

Os autores da área de estudos CTS citados nesse texto marcam um modo de conhecer nas Ciências Sociais que relaciona diretamente a forma como construímos o conhecimento com uma postura política a ser tomada pelo pesquisador. Questão fundamental a todos eles: a preocupação com o mundo que queremos construir com nossas pesquisas - em relação a minha preocupação atual: que mundo queremos construir com os psicólogos que formamos?

Inspiradas nesses autores, somos convocadas, então, a nos colocar cuidadosas quanto à nossa ação de cuidar, pois esta se constitui em nosso trabalho, nos projetos de extensão que coordenamos e na pesquisa a desenvolver no doutorado, como objeto e método de pesquisa!

Essa inspiração teórica pontua a necessidade de não só lidarmos com o que aparece, com o novo, com as dobras (Law, 2011), os desvios (Despret, 1996), mas valorizá-los, trazendo-os para a cena de estudo/pesquisa, inclusive na escrita. Como nos diz Zanella (2013), ao se debruçar sobre a forma de lidar com a cartografia das cidades em sua pesquisa, "Assim como em viagens para diferentes localidades, também na viagem/pesquisa os acasos têm seu valor. Becos, vias, vielas, piazzas e mais piazzas... Deixar-se desorientar pela sinuosidade das passagens/situações e ver o que ou quem as habita (p.38)" sublinha a necessidade de trazer para o campo de estudo o que é deixado à margem, não legitimado.

Despret (2011) nos chama atenção para a importância de atentarmos para nossas emoções, já que tendemos a, imersos nelas, não as registrarmos, "o peixe não vê a água do aquário (p. 30)" e sua implicação política. E acrescenta, "O saber dos outros transforma as nossas maneiras de nos saber" (Despret, 2011, como citado em Quadros, 2011, p.92). Quando não trazemos para a pesquisa 0 
caminho percorrido e seus atravessamentos, estamos ajudando a construir, talvez, a idealização de um mundo perfeito, perpetuando a hegemonia de um meio de construção do saber.

Esses autores nos dizem que o social não é algo que está fora de nós, que está dado, para o qual possamos olhar à distância, a fim de o pesquisarmos. O social está se fazendo em nós e "por" nós. Para sua apreensão, portanto, necessitamos de uma ciência social com métodos de pesquisa permeáveis por essa mobilidade e imprevisibilidade. Law (2004) ressalta-nos,

If the world is complex and messy, then at least some of the time we're going to have to give up on simplicities. But one thing is sure: if we want to think about the messes of reality at all then we're going to have to teach ourselves to think, to practise, to relate, and to know in new ways. We will need to teach ourselves to know some of the realities of the world using methods unusual to or unknown in social science. (p.2)

Precisamos, segundo ele, ampliar nosso repertório metodológico para dar conta do que se nos apresenta hoje como o inominável, as intuições, apreensões, sensações, legitimando o inesperado - o invisível aos olhos!

Quando nos defrontamos com o campo, acessamos não exatamente o desconhecido, mas o despreparado, o ainda não feito, o imprevisto, o não inventado também em nós ${ }^{4}$. Essa é, de fato, a grande aventura e ao mesmo tempo o risco que corremos. Se não podemos garantir o que iremos encontrar lá, não podemos prever o que acontecerá em nós (Quadros, 2011, p. 76).

A questão metodológica que se coloca é importante na medida em que defende não precisarmos abrir mão dos métodos já existentes e sim ampliá-los e não tê-los como hegemônicos, pois eles produzem um mundo do qual já não dão conta.

Law (2011), no texto Assembling the Baroque, convoca o Barroco para pensarmos nosso conhecimento do mundo, diretamente ligado ao método a ser utilizado. Se utilizarmos os métodos identificados tradicionalmente como científicos, orientados por um modelo de fazer ciência positivista, perderemos os elementos que saem do "script" e que, acreditamos, podem redesenhar toda a pesquisa: as errâncias, os desvios, as dobras, como nos traz ele no texto citado. E, mais importante, deixando de narrar essa constituição, estaremos ratificando a idéia de um mundo "perfeito", linear, passível de controle. Um mundo que pode ser apreendido em sua totalidade. Ele aponta alguns elementos que, assim como no Barroco, penso, nos 
interessam particularmente em nossas práticas de pesquisa: o Barroco reconhece coisas diferentes, que passam por uma dimensão de transcendência, que pertencem a um mundo que é extraordinário, que não se encaixam na mundaneidade e mobiliza leituras mais emocionais que racionais.

Em nosso entendimento, atentar para tais aspectos nos faz performar um tipo de ciência muito mais abrangente. Portanto, a perspectiva do Barroco seria um recurso interessante ou uma metáfora para a legitimação da produção de outro tipo de conhecimento - no GAPsi, por exemplo, aquele que se faz, como nos diz ele, nas "dobras do manto de Sta. Teresa" que, com seus artifícios fazem desaparecer a divisória interior-exterior, claro-escuro, enquadramentos metafóricos na elucidação do conhecimento que aparece. O artifício da dobra separa dentro e fora e, ao mesmo tempo, desfaz essa separação e, principalmente, para o que nos interessa nessa reflexão, nos faz apreciá-la como condição de entendimento. Um entendimento que se faz muito mais pela apreensão da realidade através dos sentidos que pela abstração. Esses elementos por si só possibilitam, talvez, modos de existência que reconheçam mais facilmente a alteridade. Será que estamos interessados em incluí-las na construção do conhecimento produzido na Academia?

Abrir espaço para o cuidar através do GAPsi , apreender suas sutilezas, seguir suas pistas, mapear suas práticas na universidade “(...) como nos romances e filmes policiais, onde cada descoberta leva sempre a outra, faz mudar de caminho, mobiliza a revisão de estratégias anteriores para seguir em frente. (Baptista, 2000, p.26)" nos parece uma prática de pesquisa, inclusive a da pesquisa a ser desenvolvida no doutorado, bastante promissora.

\section{Referências}

Baptista, L. A. dos S. (2000). A fábrica de interiores: a formação psi em questão. Niterói: Ed. UFF.

Bondía, J. L. (2002). Notas sobre a experiência e o saber de experiência. Revista Brasileira de Educação, (19), p.20-28. Recuperado em 15 de outubro, 2011 de http://redalyc. uaemex.mx/redalyc/pdf/275/27501903. pdf

Despret, V. (1996). Pathos et resistances. In A. Chauvenet, V. Despret, \& J-M. Lemarie (Orgs.). Clinique de la reconstruction: Une experience avec des réfugies en ex-Yougoslavie (pp.125194). Paris: France.

Despret, V. (2011). Leitura Etnopsicológica do Segredo. Fractal: Revista de Psicologia, 23 (1), 5-28.

Fonseca, M. L G. (2007). Sofrimento Difuso, Transtornos Mentais Comuns e Problemas de Nervos: uma revisão bibliográfica a 
respeito das expressões de mal-estar nas classes populares. Dissertação de mestrado. Escola de Saúde Publica/Fundação Oswaldo Cruz, Rio de Janeiro, RJ, Brasil.

Haraway, D. (1995). Saberes localizados: a questão da ciência para o feminismo e o privilégio da perspectiva parcial. Cadernos Pagu, 5, 07-41.

Haraway, D., \& Kunzru, H. (2009). Manifesto ciborgue: Ciência, tecnologia e feminismo-socialista no final do século $X X$. In $T$. Tadeu(Org.) Antropologia do ciborgue: as vertigens do póshumano. (pp. 33-119). 2aㅡ ed, Belo Horizonte: Autêntica Editora. (Mimo)

Latour, B. (1994). Jamais fomos modernos: Ensaio de Antropologia Simétrica. (C.I, Costa, Trad.) Rio de Janeiro: Editora 34.

Latour, B. (2008). Reensamblar lo social: uma introdución a la teoria del actor-red. (G. Zadunaisky, trad.), Buenos Aires: Manantial.

Law J. (2004). After Method: Mess in social science research. New York: Roultledge.

Law, J. (2011). Assembling the Baroque. Working Paper Series, 109. Recuperado em 28 de setembro, 2013 de http://www.cresc.ac.uk/sites/default/files/J ohnLawAssemblingT heBaroqueWP109.pdf

Miller, A. (1997). O drama da criança bem dotada: como os pais podem formar (e deformar) a vida emocional dos filhos. (Abeling-Szabol, C., Trad., ED. Rev. e atualizada) São Paulo: Summus.

Mol, A. (2002). The body multiple: ontology in medical practice. USA: Duke University Press.

Mol, A. (2008a). The logic of care: health and the problem of patient choice. USA: Routledge.

Mol, A. (2008b) Política ontológica: Algumas idéias e várias perguntas In J. A. Nunes \& R.Roque (Orgs.). Objectos Impuros: Experiências em Estudos sobre a Ciência (pp.22-40). Porto: Edições Afrontamento.

Mol, A., Moser, I., \& Pols, J.(2010). Care in Practice: On Tinkering in Clinics, Homes and Farms. Bielefeld, Alemanha: Transcript; Piscataway, NJ: Transaction.

Moraes, M. (2003). A Psicologia como reflexão sobre as práticas humanas: da adaptação à errância. Estudos de Psicologia, 8(3), 535-539.

Moraes, M. (2010). PesquisarCOM, Política Ontológica e deficiência visual, In M.Moraes, \& V. Kastrup(Orgs.). O Exercício de ver e não ver: arte e pesquisa com pessoas com deficiência visual. (pp. 26-50). Rio de Janeiro: Nau.

Quadros, L. C. de T. (2011). A construção artesanal do fazer clínico na psicologia. Tese de Doutorado. Universidade do Estado do Rio de Janeiro/UERJ, Rio de Janeiro, Brasil. 
Prestrelo, E. T.(2002). No meio do caminho, um menino... Jornal A Província, 4. Goiana: PE.

Puig de La Bellacasa, M. (2012). 'Nothing comes without its world': thinking with care. The Sociological Review, 60(2), 197-216.

Ribeiro, W. (1998). Existência essência: Desafios teóricos e práticos das Psicoterapias Relacionais. São Paulo: Summus Editorial.

Rosa, G. (1986). Grande Sertão: veredas. (31a ed.). Rio de Janeiro: Nova Fronteira.

Stengers, I. (2006) Le vierge et le neutrino: lês scientifiques dans la tourment. France: Empêcheurs de Penser em Rond.

Teixeira, M. A. P, Dias, A. C. G., Wottrich, S. H., \& Oliveira, A. M (2008). Adaptação à universidade em jovens calouros. Revista Semestral da Associação Brasileira de Psicologia Escolar e Educacional (ABRAPEE), 12(1) 185-202.

Xisto, V. (2006). E agora? In E. Vasconcelos, L. H. Frota, \& E. Simon (Orgs.). Perplexidade na Universidade: vivências nos cursos de saúde (pp.224-227). São Paulo: Editora Hucitec.

Zanella, A. V. (2013). Perguntar, registrar, escrever: inquietações metodológicas. Porto Alegre: Sulinas; Editora UFRGS.

\section{Endereço para correspondência \\ Eleonôra Torres Prestrelo}

Universidade do Estado do Rio de Janeiro

Instituto de Psicologia

Rua São Francisco Xavier, 524, $10^{\circ}$ andar, Maracanã, CEP 20550-013, Rio de Janeiro - RJ, Brasil

Endereço eletrônico: eprestrelo@gmail.com

Recebido em: 19/05/2014

Reformulado em: 23/09/2014

Aceito para publicação em: 23/09/2014

\section{Notas}

* Professora Assistente do Instituto de Psicologia da Universidade do Estado do Rio de Janeiro/UERJ. RJ. Brasil. Doutoranda em Psicologia pela Universidade Federal Fluminense/UFF na linha de pesquisa: Subjetividade, Política e Exclusão Social, orientanda do Laboratório PesquisarCOM, vinculado ao Grupo de Pesquisa Entre Redes.

${ }^{1}$ Contraponto ao ditado popular: "O que o olho não vê o coração não sente!"

2 Permito-me aqui parafrasear o pesquisarCom cunhado por Márcia Moraes (2010) ao apresentar sua perspectiva acerca da relação entre pesquisador e seu objeto de pesquisa onde ambos afetam-se mutuamente, tema que trataremos melhor no decorrer do texto.

3 Gostaria de agradecer a contribuição do grupo que compõe o Laboratório PesquisarCOM(UFF) pelas discussões empreendidas em nossas reuniões de pesquisa, que muito contribuíram para a elaboração das idéias contidas nesse artigo, pela solidariedade constante e muito especialmente, a sua coordenadora prof a Marcia Moraes pelo exemplo de um fazer encarnado na prática de "pesquisar com".

${ }^{4}$ Grifo da autora da Tese. 